\title{
Business Model for Wi-Fi Infrastructure Provider
}

\author{
E.L.Dwianti \\ Faculty of Economics \& Business, Telkom University \\ Bandung, Indonesia \\ dwiantie@gmail.com
}

\author{
M. Ariyanti \\ Faculty of Economics \& Business, Telkom University \\ Bandung, Indonesia \\ maya.ariyanti@gmail.com
}

\begin{abstract}
Wi-Fi Infrastructure Provider can promote their Wi-Fi Infrastructure to Other License Operator such as ISP and Mobile Operator. Wi-Fi Infrastructure Provider, as a learning organization, should be able to change its behaviors and mindsets as a result of experience an organization to achieve competitive advantages. The lack of frequencies and bandwidth of ISP and Mobile Operators are the opportunity for Wi-Fi Infrastructure Provider to accelerate adoption of mobile data offload. Wi-Fi Infrastructure becomes one of solution alternatives as a complementary of ISP and Mobile Operators to deliver LTE-class quality by combining 3G and Wi-Fi services. Mobile data traffic can be offloaded to Wi-Fi infrastructure. Wi-Fi Infrastructure Provider will gain a competitive sustainability and monetize the Wi-Fi Infrastructure in the same time.
\end{abstract}

Both internal and external environment are zoomed out and assessed, followed by addressing customer's objectives, their pain in deliver the service and what they gain to the value that offered, and convert into pain reliever and gain creators. The result was mapped into nine-elements using the Osterwalder's Business Model Canvas.

The nine-elements are Customer Segments ISP, Mobile Operator and Wi-Fi Provider, the Value Propositions are web service and seamless offloading, using Account Manager for Distribution Channels and Customer Relationships. Revenue Streams can be obtained from usage fee, revenue sharing, Swap AP or bulk scheme and white labeling for Company's Brand and Wi-Fi platform that has a nationwide coverage as a Key Resources. Key Activities to deliver the service are Platform \& Network management also service delivery. Key Partnerships are AP manufactures, Client Apps Developer and other Wi-Fi Provider. Cost Structure consists of Development of Platform or Network, SITAC, O\&M and provisioning.

Business model should be evaluated and reviewed periodically to adjust the environment. Organizational learning is more than individual learning and arises through the interaction of each nine components in Business Model Canvas.

Keywords-Wi-Fi; Business Model Canvas; Wi-Fi Value Proposition Design (key words)

\section{INTRODUCTION}

Shifting in the telecommunications technology drive the growth of the telecommunications industry. The growth of mobile data traffic is increasing high globally and predicted to reach 10.8 Exabyte per month in 2016. Telecommunications industry will continue to grow optimistically [1].

Mobile offload adoption acceleration driven by high mobile data traffic growth with lack of spectrum availability and bandwidth, on the other side, high cost of mobile infrastructure investment, that will become the obstacle for mobile operator to fulfill the mobile data demand. Wi-Fi is ubiquitous and the shifting to indoor mobile data traffic consumption will drive adoption of mobile offload traffic. Cisco VNI predicted that by 2017 , more than $46 \%$ of smartphone traffic and $71 \%$ of tablet traffic will be offloaded to Wi-Fi infrastructure.

The high growth of mobile chip shipment, increasing of global Wi-Fi device revenue, and the number of global public hotspot will drive $52 \%$ of mobile data traffic will be offloaded to Wi-Fi [2]. Cisco predicted that $72 \%$ of mobile data traffic will be generated by mobile video, align with significant growth of video application on mobile device. Mobile video content need higher speed and consume more volume bandwidth compared to other mobile application, it means mobile video will drive the growth of mobile data offloading.

Indonesian mobile data payload projected still grow with $47.6 \%$ CAGR, at least $47 \%$ generated from Telkomsel mobile data payload. Increasing of mobile data payload combined with lack of spectrum and bandwidth are an opportunity for Wi-Fi infrastructure provider to deliver mobile data offloading for mobile operators.

The lack of frequencies and bandwidth of ISP and Mobile Operators are the opportunity for $\mathrm{Wi}-\mathrm{Fi}$ Infrastructure Provider to accelerate adoption of mobile data offload. Wi-Fi Infrastructure becomes one of solution alternatives as a complementer of ISP and Mobile Operators to deliver LTEclass quality by combining $3 \mathrm{G}$ and Wi-Fi services. Mobile data traffic can be offloaded to Wi-Fi infrastructure. Wi-Fi Infrastructure Provider will gain a competitive sustainability and monetize the Wi-Fi Infrastructure in the same time.

Wi-Fi infrastructure provider, as a learning organization, should be able to change its behaviors and mind-sets as a result of experience an organization, to deliver its $\mathrm{Wi}-\mathrm{Fi}$ infrastructure to another operator as a competition strategy. This is because the adoption of a new type of network 
infrastructure with innovative technology (e.g.,broadband in telecommunications) may lead to price reductions or the provision of better quality products [3].

This paper presents a business model for Wi-Fi infrastructure provider to deliver Wi-Fi for mobile operators and ISPs. The business model refer to Alexander Osterwalder Business Model Canvas [4-5]. The nine-element of BMC was assessed for Indonesian Mobile Operators and Internet Service Providers and reported in this paper.

\section{THE MODEL}

The nine-elemen of Business Model Canvas (BMC) was derived from Osterwalder. The environment was zoomed out to analyze the strategic situation. As an external environment, there are market forces, key trends, industry forces and macro economics forces [6]. Key trends are driven by Indonesian Regulatory trends, Wi-Fi technology trends, Indonesian societal and cultural trends, also Indonesian socioeconomics trends. Industry forces are the competitors (i.e Other Wi-Fi Infrastructure Provider) and new entrants, value chain supplier like AP equipment manufactures. Market forces are coming from Mobile Operators and ISPs segment that lack of frequencies and capacities. As a macroeconomic forces, global market shown an increasing growth in mobile data traffic with limited capital expenditure.

Osterwalder's Value Proposition Canvas was used to address the company's value proposition and customer pain [7-8]. For company's internal capabilities, Osterwalder's $\mathrm{BMC}$ was used to assess each of nine elements.

\section{VALIDATION PROCESS}

In order to check the business model formulation, a validation was conducted by comparing the opinion of decision makers in Wi-Fi Infrasrtuctur Provider and an expert in Telecommunication Industry. At least three decision makers, three account managers and one expert involved in validation process.

\section{A. Value Proposition Canvas}

Value Proposition Canvas was used to invent and improve value propositions of Wi-Fi Infrastructure for Licensed Operators, The tools was very useful for managing and creating new value propositions and business models that meet customer profiles.

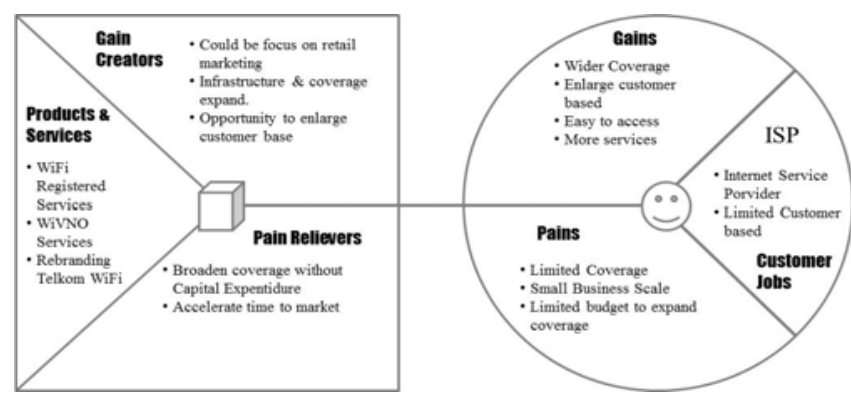

Fig. 1. Value Proposition Canvas for ISPs

Figure 1 and 2 show designated ISP and Mobile Operator's objectives, their pains and gains to Wi-Fi Infrastructure services value. Both internal and external environment are zoomed out and assessed, followed by addressing customer's objectives, their pain in deliver the service and what they gain to the value that offered, and convert into pain reliever and gain creators. The value proposition will be the pain reliefer, in the same time as a gain creators for customers. The result was mapped into nine-elements using the Osterwalder's Business Model Canvas

Value can be created by helping a customer get certain jobs done. Since the objectives of ISPs and Mobile Operators are distinct, the Value Propositon Canvas should be different. Each of both ISP and Mobile Operators jobs had their pains in delivering services, and Wi-Fi Infrastructure will create gains to deliver their products and services. This arrangement allows ISPs and Mobile Operators to focus on running their retail marketing.

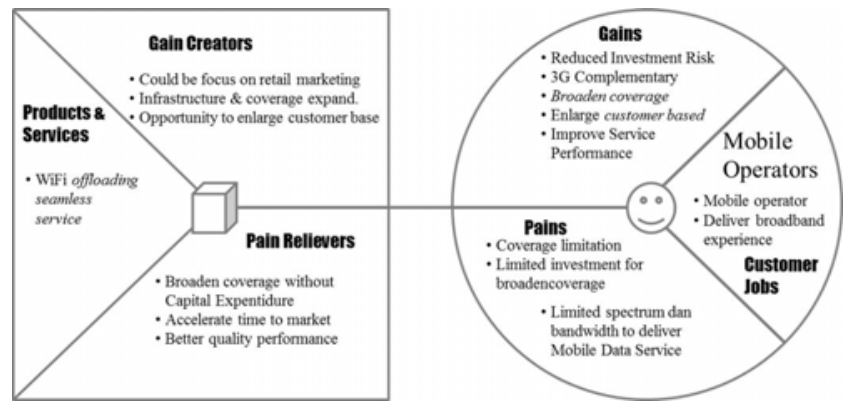

Fig. 2. Value Proposition Canvas for Mobile Operators

Services for Mobile Operators are seamless offloading thru white labeling product, while ISP can be served in registered and Wi-Fi Virtual Network Operator. ISP also can rebrand Wi-Fi Infrastructure's product.

\section{B. Business Model Canvas}

A business model describes the rationale of how an organization creates, delivers, and captures value. A business model can best be described through nine basic building blocks that show the logic of how a Wi-Fi Infrastructure Provider intends to make money. The nine blocks cover the four main areas of a business : customers, offer, infrastructure, and financial viability. The business model is like a blueprint for a strategy to be implemented through organizational structures, processes, and systems [5].

Wi-Fi Infrastructure Provider serves ISP, Mobile Operator and WiFi Provider as Customer Segments, these customers are segmented by their product and services [9]. Value proposition seeks to solve customer problems and satisfy customer needs. The Value Propositions of Wi-Fi Infrastructure Provider creates value of products and services for ISP and Mobile Operator to solves their problems such as lack of frequencies and bandwidth capacities. As described on figure 1 and 2, the 
Value Propositions for Mobile Operators are seamless offloading thru white labeling product, while Value Propositions for ISP are web registered services and $\mathrm{Wi}-\mathrm{Fi}$ Virtual Network Operator. ISP also can rebrand Wi-Fi Infrastructure's product.

Value propositions are delivered to customers through communication, distribution, and sales Channels. Account Manager will perfectly suit for B2B scheme as Distribution Channels and maintain Customer Relationships in the same time. Account Manager serve several functions, including building awareness about company's products and services, helping customers evaluate and improve Value Proposition, costumizing products and services, delivering the service and providing post-purchase customer support. Customer relationships are established and maintained by Account Manager. Account Manager is needed to acquire new customer, retain customer and upselling.

Revenue streams is a result of value propositions that is successfully offered to customers. Revenue Streams can be obtained from Mobile Operator's usage fee. Revenue streams also can be obtained from revenue sharing, Swap AP or bulk scheme from both ISP and Other Wi-Fi Infrastructure Provider. Especially for ISP, revenue streams can be obtained from white labeling Company's Brand.

Key resources are the assets required to offer and deliver the previously described elements. Nationwide coverage WiFi platform is a Key Resources of Wi-Fi Infrastructure Provider. A large number of AP is also the key resources with excellent perfomance.

Key Activities to deliver the service are Platform \& Network management to maintain service performance and service delivery. These activities are including provisioning, deployment and AP's operation \& maintenance.

Companies create alliances to optimize business models, reduce risk, or acquire resources. Key Partnerships for Wi-Fi Infrastructure Provider are AP manufactures as key suppliers, Client Apps Developer to develop applications and other WiFi Provider to accelerate AP deployment.

Creating and delivering value, maintaining Customer Relationships, and generating revenue all incur costs. Cost Structure consists of Development of Platform or Network, SITAC (Site Acquisition), O\&M and provisioning.

The nine-elements of BMC for ISP and Mobile Operator shown in figure 3 . These BMC assessed with both external and internal environment combined with Value Proposition Canvas. Yellow are for all customer segments, red are for ISP dan other WiFi Provider, while blue are only for Mobile Operator .

Business model should be evaluated and reviewed periodically to adjust the environment. Organizational learning is more than individual learning and arises through the interaction of each nine components in Business Model Canvas.

\section{CONCLUSIONS}

The lack of frequencies and bandwidth of ISP and Mobile Operators are the opportunity for WiFi Infrastructure Provider. WiFi Infrastructure Provider, as a learning organization, should be able to change its behaviors and mind-sets as a result of experience an organization to achieve competitive advantages. This paper mapped the WiFi Infrastructure Provider into a Business Model using nine-elements Osterwalder's Business Model Generation. WiFi infrastructure provider can deliver its $\mathrm{WiFi}$ infrastructure to another operator as a competition strategy. WiFi Infrastructure Provider will gain a competitive sustainability and monetize the WiFi Infrastructure in the same time [10].

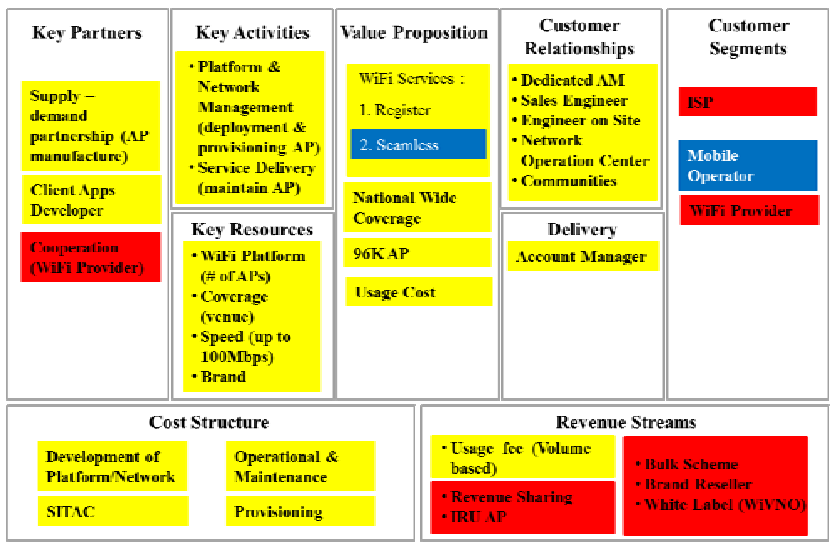

Fig. 3. Business Model Canvas for ISP, Mobile Operator and WiFi Provider

This business model should be evaluated and reviewed periodically to adjust the environment, both internal and external. Organizational learning (OL) [11] is more than individual learning and arises through the interaction of each nine component in Business Model Canvas.

\section{References}

[1] CISCO and or its affiliates, "Cisco Visual Networking Index: Global Mobile Data Traffic Forecast Update, 2014-2019," CISCO, 2015.

[2] N. Bruin, "PT Telkom Workshop Successful Telco Wi-Fi," Huawei Technologies, Jakarta, 2014

[3] K. Hori \& K. Mizuno, "Competition Schemes and Investment in Network Infrastructure under Uncertainty," Faculty of Economics, Ritsumeikan University, 2007.

[4] A. Osterwalder \& Y. Pigneur, Business Model Generation, John Wiley and Sons, Inc., New Jersy: Hoboken, 2010, ISBN: 978-0-470-87641-1

[5] B. C. Madu, "Vision: the relationship between a firm's strategy and business model", Journal of Behavioral Studies in Business, Vol. 6, 2013.

[6] G. Camponevo \& Y. Pigneur, "Business Model Analysis Applied to Mobile Business", International Conference on Enterprise Information Systems, Vol. 4, 2003, pp. 173-183.

[7] A. Osterwalder, Y. Pigneur, G. \& A. Smith, Value Proposition Design, John Wiley and Sons, Inc., New Jersy: Hoboken, 2014, ISBN 9781118968055 . 
[8] Christensen, C. M., S. D. Anthony, G. Berstell, and D. Nitterhouse, "Finding the Right Job for Your Product," MIT Sloan Management Review, Vol. 48, Issue 3, 2007

[9] Hetting, C, "Seamless WiFi Offload: A Business Opportunity Today. Aptilo Networks," 2013.

[10] Mishra, P, CISCO, "WBA WiFi Congress," 2013.

[11] E. Mitleton-Kelly, "What are the Characteristics of a Learning Organization?", Global Environmental Management Initiative, 2003, accessible at Gemi.org 